\title{
Analysis of constraints in dairy farming in Kerala-multi stakeholder perspective
}

\author{
Smitha S, MCA Devi, Letha Devi G and Subash S
}

Received: 11 December 2018 / Accepted: 01 April 2019 / Published online: 22 June 2019

(c) Indian Dairy Association (India) 2019

\begin{abstract}
The study was undertaken in Kerala to evaluate the challenges of dairy farming at research, extension and farmers' level. A total number of 200 respondent farmers and stakeholders from research and extension domain in the study area were selected randomly. Garret's ranking technique was adopted to analyze the constraints faced by the stakeholders in the study area. The major constraint faced by the dairy farmers were the high cost of cattle feed and high cost of veterinary service and medicine was the second major constraint experienced by the farmers. The important constraints faced by the officials involved in extension services included implementation of large number of schemes in Panchayat and block level followed by lack of transportation facilities to make field visit. In research system, the major constraint was the prioritized mandate of teaching and extension followed by time constraint for technology transfer.
\end{abstract}

Keywords: Constraints, dairy farming, stakeholders, Kerala State

Smitha $S(\square)$

Centre for Gender Studies in Agriculture and Farm Entrepreneurship

Development, Kerala Agricultural University, Vellanikkara-680 656,

Thrissur, Kerala, India

Email: smithasiva88@gmail.com

MCA Devi

Division of Dairy Extension, SRS of ICAR-NDRI, Adugodi- 560 030, Bengaluru, Karnataka, India

Letha Devi G

National Institute of Animal Nutrition and Physiology, Adugodi-

560030, Bangalore, Karnataka, India

Subash S

Division of Dairy Extension, SRS of ICAR-NDRI, Adugodi-560030, Bengaluru, Karnataka, India

\section{Introduction}

Dairying is one of the most promising allied sectors of the agriculture. India is endowed, as the largest milk producer (165.4 million tons) and consumer contributing 19.00 percent to world milk production. India is blessed with mega livestock diversity, with largest livestock population (512.05 million), consisting of about 57.00 percent of world buffalo and 16.00 percent of world cattle population in the World (GOI, 2018). However, the country still faces a production shortfall due to increase in demand from the growing population but with low productivity of Indian cattle. Various efforts, therefore, are underway to generate and disseminate improved livestock practices/technologies to improve the livestock productivity. The livestock sector in India is solely dependent on small and marginal farmers, who follow limited scientifically recommended practices. Institutional, infrastructural and strategic reorientation need to be made to ensure effective dissemination and adoption of the various newer and useful technologies in the field. The mode of technology transfer needs to ensure that the livestock farmers reap the benefit of investment in livestock research. The efforts of government will be augmented through involvement of private sector, NGOs and progressive farmers and their organizations (GOI, 2013). Before assessing the technology gap among dairy farmers, we should analyze, the constraints faced by the stakeholders involved in dairy farming, so as to facilitate for strategic planning and decision support. The study was undertaken in Kerala to evaluate the limitations of dairy farming experienced at various level in the perspective of research, extension and farmer.

\section{Materials and methods}

Exploratory research design was employed to provide answer to selected research question. The methodology is discussed under following subheads:

\section{Area of the study and sampling procedure}

The study was conducted in Kerala State owing to the high potential for increased dairy production, as 87.00 per cent of total cattle population of Kerala is exotic/cross bred cattle. Based on the topographical parameters, Kerala could be divided as 
Northern Region, Central Region, Southern Region and High Range Region. From each region the one representative district was selected for the study through random sampling technique. From each of the selected district, two villages were selected and twenty five farmers from each of the selected villages were randomly selected for the study. The total number of the respondent farmers comprised 200 from the selected villages. Stakeholders from research and extension domain in the study area were selected randomly. Data collection was done using well structured, pre-tested and standardized interview schedule developed for the intended purpose. The first-hand information was taken from the respondents during the study, and thereafter with the help of experts and review of literature the list of constraints were selected. Garret's ranking technique was adopted to analyze the constraints faced by the stakeholders in the study area. The respondents were asked to rank the given factors in the schedule. The order of merit thus given by the respondents was converted into ranks by using the following formula:

Per cent Position $=\frac{100\left(R_{i j}-0.05\right)}{N_{j}}$

Where,

$R_{i j}=$ Rank given for the $i^{t h}$ item by $j^{\text {th }}$ respondent

$N_{i j}=$ Number of items ranked by $j^{\text {th }}$ respondent.

The percent position of each rank was converted into scores referring to the Table given by Garrett and Woodworth (1969). For each factor, the scores of individual users were added together and divided by the total number of respondents. Thus, the mean scores of the constraints were ranked by arranging in descending order, ranks were assigned and most important factors were identified.

\section{Results and discussion}

\section{Constraints faced by the dairy farmers in the study area}

Table 1 shows the percent score values and the various constraints were ranked. From Table 1, it could be inferred that the major constraints faced by the dairy farmers were high cost of cattle feed. This might be due to the fact that, as Stated in Agriculture Development Policy (Anonymous, 2015), Dairying in Kerala is under intensive system to a line of 75.00 percent and the rest 25.00 percent under semi intensive system. Intensive system of dairying consumes most of the expenditure for feed and fodder which constitutes 80.00 percent of the total cost of production. The high feed costs reduce the gap between cost of production and procurement, resulting in low profitability for farmers. Hence it is mandatory that the price of milk should be based on the cost of production, to make the dairy sector sustainable. Sabapara (2016), who studied the constraints of dairy farming in Coastal Areas of Southern Gujarat, and revealed that vast majority $(76.00 \%)$ of the farmers reported high cost of cattle feed as their major constraint.

High cost of veterinary service and medicine was the second major constraint felt by the farmers. Rajpoot et al. (2018) in their study on constraints faced by dairy farmers while adopting animal management practices in Dhar District of Madhya Pradesh indicated that high cost and lack of veterinary facility in village are the most important constraints faced by the farmers in adopting management practices for their cattle. Veterinary doctor service and medicine at veterinary dispensary are free of cost for the farmers. But all the medicines prescribed by the doctors are not available in the dispensary and farmers have to buy the costly medicines and injections by themselves. Also in cases of emergency, farmer has to call Doctor/Livestock inspector to check the animal at farm. For this, the farmer has to bear the charges for his/her transportation which hikes the treatment charges for animals. Some societies have their own doctors and diagnostic and treatment services at nominal charges were offered to the members of society. Other societies can also pursue the same by contracting the services of private or retired professionals to complement the public veterinary doctors. All medicines should be made available through dispensaries or through subsidized cost, which will be more supportive for the farmers.

Non availability of green and dry fodder round the year was the next perceived constraints by the farmers. With the shift in cropping pattern of Kerala, the area under rice has been falling at an alarming rate ever since the 1980s. From 8.82 lakh hectare in 1974-75, the paddy area has come down to 1.96 lakh hectare in 2015-16. (Economic review, 2015). leading to drastic reduction in the availability of straw for feeding cattle. It is estimated that the State produces only 60.00 per cent of the roughage requirement for cattle in Kerala(Anonymous, 2015). And the straw is being brought in from neighboring States at an exorbitant rate. During survey (October 2018 to February 2018) farmers reported that they are buying straw and green fodder at a rate of Rs.38.00/10 $\mathrm{kg}$ and Rs. 3.50/kg respectively, which make dairy farming. The situation can be tackled by utilizing the locally available feed resources like cereals, legumes, tubers, jack fruit, etc in more judicious way. Nagrale et al. (2015) analyzed the constraints faced by dairy farmers in Vidarbha Region of Maharashtra and reported that lack of availability of green fodder was the major feeding constraint faced by the dairy farmers.

High labor cost was another important constraints faced by the farmers, Kerala is one of the State with the highest labor wage rates ranging from Rs. 600-700/day. High labor cost has forced many of the farmers to keep away from labor-intensive agriculture and dairying activities. In order to tackle the labor problem in farming sector and to reduce the cost incurred, mechanization 
will be the alternative strategy to be adopted. Governmentinitiated schemes, with subsidies for procurement of farm equipments need to be adopted. Family labor is one alternative perceived and being practiced.

Another constraint reported by farmers was lack of need based training. Many training programmes are offered by different institutions as Dairy Development Department, Animal Husbandry Department and Cooperative Societies. As expressed by farmers' duplication of focus areas of training need to be taken care. Need based training programmes in the area of disease management; low cost balance feeding should be focused. GOI (2013) highlighted the precarious status of livestock extension and advisory services and the need to strengthen it. Rajpoot et al. (2018) in their study on constraints faced by dairy farmers while adopting animal management practices in Dhar District of Madhya Pradesh reported that lack of technical knowledge to manage the dairy animal is a major constraint faced by the dairy farmers.

High cost of credit was another important constraint, perceived by the farmers. Farmers are getting agricultural loan at a much lower rate (4.00 per cent per annum) with an interest subvention from both Central and State Government under the priority sector lending, the credit needs of the cattle owners are denied of any such concessions. Cattle loans are under industry sector are at an interest rate of above 12.00 percent per annum, which is not affordable especially for small and marginal farmers who own a major share of the cattle population and is a hurdle for them to extend the farming activities. This needs immediate attention at various levels for policy guidelines, to guarantee the viability of dairy farming among small and marginal farmers. Sreeram (2017) in his study on innovation system in evolving dairy value chains in Kerala reported the high interest rate on cattle loan as a serious constraint faced by the farmers.

Non-availability of high yielding milch animals for purchase is one of the important constraint expressed by the respondent farmers. The rearing cost of dry or young animals are so high that farmers tend to ignore young ones or cull dry ones, as it is profitable, due to the high demand and price for beef in the State. A farmer will have to spend nearly Rs.45,000-50,000 for the scientific rearing of a Heifer till it becomes a milch cow.( Anonymous, 2017). It is easier for the farmer to sell the calf at a young age and purchase a cow in milk as and when required. This has led to a reduction in the good quality young stock in the State and we are forced to depend on the neighboring States for purchasing high producing cross bred cows. So many schemes like Heifer Rearing Units under Milk and Milk Shed Development Programme, Calf Adoption Scheme etc. by State government, which aims at increasing the number of highproducing cross-bred cows in the State. Also inadequate land for fodder cultivation and complete stall feeding increase the cost of production for farmers.

\section{Constraint faced by the stakeholders involved in extension services}

The study also made an attempt to assess the major constraints faced by the officials involves in extension services to the dairy farming community. The major stakeholders involved in extension services were veterinary doctors and dairy extension officers. The major constraints were identified and prioritized using garret ranking technique as follows

Table 1 Constraints faced by the dairy farmers

\begin{tabular}{lllc}
\hline No. & Items & Percent Score & Rank \\
1. & High cost of cattle feed & 74.64 & 1 \\
2. & High cost of veterinary service and medicine & 72.66 & 2 \\
3. & Non availability of green and dry fodder round the year & 63.65 & 3 \\
4. & High labour cost & 59.49 & 4 \\
5. & Lack of need based training & 54.52 & 5 \\
6. & High interest rate on cattle loan & 41.88 & 6 \\
7. & Non-availability of high yielding milch animals & 41.25 & 7 \\
8. & Inadequate land for fodder cultivation & 40.29 & 8 \\
\hline
\end{tabular}

Table. 2 Constraints faced by the stakeholders involved in extension services

\begin{tabular}{lllc}
\hline No. & Items & Percent score & Rank \\
\hline 1 & Time constraint for technology transfer activities & 73.60 & 1 \\
2 & Commutation constraint to reach field/farm & 67.90 & 2 \\
3 & Time bound scheme implementation & 64.00 & 3 \\
4 & Inadequate training on new technologies & 51.90 & 4 \\
5 & Extra duty of other office & 46.93 & 5 \\
6 & Inadequate supporting staff & 40.23 & 6 \\
\hline
\end{tabular}


Table 3 Constraints faced by the stakeholders involved in research

\begin{tabular}{lllc}
\hline No. & Items & Percent score & Rank \\
\hline 1 & Priorities of teaching and research rather than extension & 69.00 & 1 \\
2 & Time constraint for technology transfer & 60.00 & 2 \\
3 & Transportation constraints for field visits & 38.00 & 3 \\
4 & Inadequate fund allocation for extension programmes & 34.00 & 4 \\
5 & Low level of involvement/participation of farming community & 32.00 & 5 \\
\hline
\end{tabular}

Table 2, indicates that the major constraint faced by the officials involved in extension services was time constraint for technology transfer activities. Owing to the set targets for scheme implementation and routine table work including beneficiary identification to accounting, the dairy extension officers were more oriented towards time bound implementation activities such as distributing inputs to beneficiaries, while veterinary doctors were more focused on animal care. Kaur and Kaur (2013) studied linkage mechanism of research-extension-farmer with market in Punjab observed that the linkages between Agriculture Development Officers (ADOs) and farmers vary from non-existent to weak because they are more involved in distributing inputs and subsidies to the farmers and are burdened with high targets.

Commutation constraint to reach field was the next important constraint faced by the officials as they have to rely on public transportation facilities, which was time consuming. Das and Borua (2017) studied constraints faced by Agricultural Technology Management Agency (ATMA) extension functionaries of Assam, India and concluded that lack of efficient means of transportation for functionaries is the major constraint faced by them.

Lack of adequate training on new technologies/refresher training programmes was another constraint faced by the officials. Rathore et al. (2008) in their study on analysis of research - extension farmer linkage in the Arid Zone of India indicated that the field level extension personnel were having more contact with the farmers but they were able to provide technical knowledge up to the limited extent. Kumar et al. (2012) analyzed status and constraints of extension service and reported that the lack of well trained subject matter specialist at different levels is largely responsible for the poor research-extension linkages and the lack of integration across crop and livestock systems.

Additional charges of other office/block with inadequate supporting staff leads to more time for table/office related work and less on field visit were the other constraint faced by the extensionists engaged in extension activities.

\section{Constraint faced by the stakeholders involved in research}

The study also made an attempt to analyze the major constraints faced by the officials of research system. The major stakeholder involved in livestock research in the State are Kerala Veterinary and Animal Sciences University and Kerala Livestock
Development Board. The major constraints as expressed by the selected respondents were identified and prioritized using garret ranking technique and presented in table 3 .

The major constraints faced by the researchers were prioritized mandatory activities of teaching and research rather than extension. Also they have clinics and farmers training programmes to focus. Kaur and Kaur (2013) on their study on linkage mechanism of research-extension-farmer with market in Punjab reported that extension specialists of Punjab Agricultural University (PAU) had non-existent to weak linkages with farmers which may be because; apart from extension they have teaching and partially the research mandates too.

The other constraint faced by the researchers was the lack of transportation facilities to make frequent visit to farmers' field. Inadequate fund allocation from government for extension programmes and low participation of farming communities in research activities are the other constraints mentioned by the researchers from the university.

\section{Conclusions}

Efforts are underway for improving the productivity of livestock in the State through various schemes and programmes. But any programmes/schemes to improve livestock production should focus on the majority marginal and smallholder farmers who are the major contributors of the State. The challenges experienced by stakeholders in technology dissemination need to be explored and suitable strategies with practical utility to be integrated to ensure effective technology reach among dairy farmers.

\section{References}

Anonymous (2015) Agricultural Development Policy. Government of Kerala

Anonymous (2017) Annual plan report, 2016-17, Dairy Development Department. Government of Kerala

Das P, Borua S (2017) Constraints faced by Agricultural Technology Management Agency extension functionaries of Assam, India and their suggestions to overcome them. . Asian J Agric Extension Econ Sociol17(1): 1-7

Economic Review (2015) Retrieved from https://kerala.gov.in/economicreview

Garrett HE and Woodworth RS (1969) The significance of the difference between means and other statistics. Statistics in Psychology and Education (New York: David McKay Co. Inc., 1966): 228 
GOI (2013) National Livestock Policy, Department of Animal Husbandry, Dairying and Fisheries, Government of India, New Delhi

GOI (2018) Annual Report 2016-17, Ministry of Statistics and Programme Implementation, Sardar Patel Bhawan, Sansad Marg, New Delhi

Kaur M, Kaur R (2013) Linkage Mechanism of Research-Extension-Farmer with Market in Punjab. Indian Research Journal of Extension Education 13(3): 19-24

Kumar U, Kumar A, Thakur PK (2012) Status and Constraints of Extension Services. Book: Status of Agricultural Development in India 479492

Nagrale BG, Datta KK, Chauhan AK (2015) An Analysis of constraints faced by dairy farmers in Vidarbha Region of Maharashtra. Indian J Dairy Sci 68(4): 390-394
Rajpoot JS, Kirad KS, Badaya AK, Chauhan SS (2018) Constraints Faced by Dairy Farmers while Adopting Animal Management Practices in Dhar District of Madhya Pradesh, India. Int J Curr Microbiol Appl Sci 7(1): 3163-3166

Rathore S, Intodia SL., Singh RP (2008) Analysis of research-extensionfarmer linkage in the Arid Zone of India. Indian Res J Extension Educ 8(3):69-72

Sabapara GP (2016) Constraints of dairy farming in Coastal Areas of Southern Gujarat. Indian J Anim Prod Manage 32 (1-2): 91-94

Sreeram V (2017) Unravelling the innovation system in evolving dairy value chains in Kerala. Doctoral dissertation. NDRI. Karnal 